\title{
Chronic Hepatitis B Virus infection
}

\author{
C. Carretero, M. Herráiz
}

\section{RESUMEN}

Existen muchos factores implicados en la patogénesis de la infección crónica por el virus de la hepatitis B (VHB), como por ejemplo características del virus, la ingesta de etanol, la coinfección con otros virus (VHC, $\mathrm{VIH}, \mathrm{VHD}$ ), e intervenciones terapéuticas como el uso de fármacos citotóxicos o inmunosupresores, o agentes antivirales específicos. Las características clínicas, patológicas y serológicas de la hepatitis crónica por VHB, además, son muy heterogéneas.

Se puede reconocer la infección crónica por VHB ante la persistencia del antígeno Australia (HBsAg) durante más de seis meses. La presencia de HBeAg se suele asociar a la replicación viral activa y puede ser medida por la cantidad de DNA-VHB presente en el suero o bien por la expresión hepática de HBcAg. El daño hepático que se produce en la hepatitis crónica por VHB no es tanto por el efecto del virus sobre los hepatocitos sino por la reacción inmune que éste provoca en el huésped. Por ello puede verse cierta correlación inversamente proporcional entre la intensidad de la replicación viral y el grado de inflamación hepática. La presencia de hepatitis crónica activa en la biopsia inicial no se ha asociado al desarrollo de cirrosis así como tampoco el diagnóstico histológico de hepatitis crónica persistente puede asegurar que se vaya a desarrollar cirrosis en un futuro.

Palabras clave. Replicación viral. Hepatitis crónica. Cirrosis.

An. Sist. Sanit. Navar. 2004; 27 (Supl. 2): 27-32.

\begin{abstract}
Many factors are involved in the pathogenesis of chronic hepatitis B virus infection (HBV), such as, for example, characteristics of the virus, ethanol intake, coinfection with other viruses (HCV, HIV, HDV), and therapeutic interventions such as the use of cytotoxic drugs or immunosuppressors, or specific antiviral agents. The clinical, pathological and serological characteristics of chronic hepatitis B virus infection are besides very heterogeneous.

Chronic HBV infection can be recognised facing persistence of the Australia antigen (HBsAg) for more than six months. The presence of $\mathrm{HBeAg}$ is usually associated with active viral replication and can be measured by the quantity of DNA-HBV present in the serum or by the hepatic expression of HBcAg. The hepatic damage that is produced in chronic hepatitis due to $\mathrm{HBV}$ is not so much due to the effect of the virus on the hepatocytes as to the immune reaction that it provokes in the host. For this reason a certain inversely proportionate correlation can be observed between the intensity of viral replication and the degree of hepatic inflammation. The presence of active chronic hepatitis in the initial biopsy has not been associated with the development of cirrhosis, nor does the histological diagnosis of persistent chronic hepatitis guarantee that cirrhosis will be developed in the future.
\end{abstract}

Key words. Viral replication. Chronic hepatitis. Cirrhosis.
Servicio de Digestivo. Área Funcional de Digestivo. Clínica Universitaria de Navarra. Pamplona.

\section{Correspondencia: \\ Dra. M. Herráiz \\ Servicio de Digestivo \\ Clínica Universitaria \\ Avda. Pío XII, 36 \\ 31008 PAMPLONA}

Tfno: 948255400 - Fax: 948296500

E-mail: ccarretero@unav.es 


\section{INTRODUCCIÓN}

La infección por el virus B de la hepatitis (VHB) es un problema de salud pública importante. Aproximadamente el 5\% de la población mundial está infectado por el VHB; de éstos, entre el 50 y el 70\% tienen replicación viral activa y están en riesgo de sufrir enfermedad hepática progresiva. El VHB es responsable de aproximadamente 1,2 millones de muertes anuales ${ }^{1,2}$.

Como se ha explicado en capítulos anteriores, la transmisión del VHB es principalmente por vía parenteral ${ }^{3}$. El riesgo de cronificación varía enormemente en función de la edad de adquisición de la enfermedad. La mayor parte de los adultos infectados se recuperan totalmente y consiguen la desaparición del HBsAg. En los pacientes con VHB adquirido por transmisión vertical, aproximadamente el $90 \%$ acaba desarrollando una infección persistente responsable de enfermedad hepática progresiva. Los pacientes con infección crónica por VHB tienen mayor riesgo de desarrollar cirrosis y hepatocarcinoma.

\section{HISTORIA NATURAL}

La infección crónica por VHB lleva consigo un aumento en la morbimortalidad por complicaciones hepáticas. Las características clínicas, patológicas y serológicas son muy heterogéneas. Los pacientes pueden tener lesiones hepáticas mínimas, hepatitis crónica de distinta severidad, cirrosis, hepatocarcinoma o no presentar evidencia de enfermedad hepática.

Existen muchos factores implicados en la patogénesis de la infección y en la historia natural de la infección, como por ejemplo el genotipo viral, la persistencia de la replicación, la aparición de mutantes virales o la integración del material viral en el genoma de los hepatocitos. Otros factores implicados pueden ser la ingesta de etanol, la coinfección con otros virus (VHC, $\mathrm{VIH}, \mathrm{VHD} .$. ), intervenciones terapéuticas como el uso de fármacos citotóxicos o inmunosupresores, o agentes antivirales específicos $^{4}$.

Se puede reconocer la infección crónica por VHB ante la persistencia del antígeno Australia (HBsAg) durante más de seis meses ${ }^{5}$. En la práctica clínica los portadores crónicos de HBsAg pueden ser divididos en dos grupos serológicos fácilmente identificables, aquellos que son $\mathrm{HBeAg}_{+} \mathrm{y}$ aquellos que son anti-HBe+. Esta distinción tiene importancia pronóstica $^{6}$ (Tabla 1).

El ciclo de replicación del VHB no es directamente citotóxico para los hepatocitos, como puede observarse en el hecho de que muchos de los portadores de VHB están asintomáticos y tienen mínimo daño parenquimatoso. Es la respuesta inmune del huésped (mediada principalmente por los linfocitos T) hacia los antígenos virales existentes en los hepatocitos quien determina el principal daño hepático. Pacientes con inmunodeficiencias, infectados con el VHB, con frecuencia tienen mínimo daño hepático, pero altas tasas de DNA viral ${ }^{3}$.

\section{RESPUESTA INMUNE FRENTE AL VHB $^{1}$}

El VHB es capaz de causar infección crónica en pacientes inmunocompetentes. A pesar de una eficaz respuesta inmune del huésped, existen mecanismos por esclarecer que permiten la persistencia del VHB. La respuesta inmune específica frente al VHB está mediada por las células presentadoras de antígenos (macrófagos y células dendríticas) que presentan partículas virales a los linfoci-

Tabla 1. Tabla resumen de serologías del VHB

\begin{tabular}{lccccc}
\hline & HBsAg & Anti HBs & Anti HBc IgM & Anti HBc IgG & HBeAg \\
\hline Hepatitis aguda & + & - & + & - & + \\
\hline Hepatitis crónica & + & - & - & + & $+/-$ \\
\hline Vacunación & - & + & - & - & - \\
\hline
\end{tabular}


tos $\mathrm{B}$ y linfocitos $\mathrm{T}$ helper y citotóxicos. La respuesta inmune implica una respuesta humoral, que inactiva las partículas virales mediante la formación de complejos antígeno-anticuerpo, y una respuesta $T$ citotóxica frente a los antígenos de los hepatocitos infectados.

El objetivo de la respuesta humoral es la producción por parte de las células B de anticuerpos capaces de eliminar los virus circulantes y de proteger frente a la reinfección; es por ello, por lo que los anticuerpos anti-HBs son vitales para el aclaramiento de los virus. Esta respuesta de anticuerpos frente al HBsAg es un proceso mediado por los linfocitos $\mathrm{T}$ y puede observarse en pacientes que aclaran el virus y se recuperan de una infección aguda. El papel de la respuesta humoral frente a los antígenos de la nucleocápside (HBcAg y HBeAg) está por determinar.

El inicio de una respuesta inmune celular frente a antígenos virales requiere el reconocimiento a través de receptores específicos de células $\mathrm{T}$. Los linfocitos CD4+ reconocen partículas virales que derivan de la fagocitosis y proteolisis de las proteínas del VHB y que se presentan en el contexto MHC-II. Con la activación de los receptores específicos de células $\mathrm{T}$, los CD4+ colaboran en la respuesta inmune mediante la activación y estimulación de los linfocitos T citotóxicos (CD8+). Los linfocitos $\mathrm{T}$ reconocen a través de su receptor específico de células T, partículas virales sintetizadas. Esto provoca la activación de los linfocitos que responden causando la lisis de los hepatocitos infectados. Por otro lado los CD8+ pueden eliminar la infección del VHB presente en los hepatocitos sin dañar las células hepáticas infectadas. Esto se consigue mediante la secreción de citoquinas antivirales como el factor de necrosis tumoral $\alpha$ y el interferón $\gamma$.

Los linfocitos T CD8+ tienen doble efecto:

a) Pueden causar daño hepático por efecto citolítico, lo cual puede provocar lesiones de hepatitis aguda y crónica.

b) Eliminar el VHB mediante mecanismos no citolíticos.

\section{SEROCONVERSIÓN HBeAg Y EL ESTADO DE PORTADOR SANO DE HBsAg}

La presencia de HBeAg se suele asociar a la replicación viral activa la cual puede ser medida por la cantidad de DNA-VHB presente en el suero o bien por la expresión hepática de HBcAg. Parece ser que el daño hepático que se produce en la hepatitis crónica por VHB no es tanto por el efecto del virus sobre los hepatocitos sino por la reacción inmune que éste provoca en el huésped; es por ello, que puede verse cierta correlación inversamente proporcional entre la intensidad de la replicación viral y el grado de inflamación hepática.

En la historia natural de la hepatitis crónica $\mathrm{HBeAg}+$ podemos observar tres fases ${ }^{2,7}$ :

\section{Primera fase: inmunotolerancia}

Inicialmente los pacientes están asintomáticos, presentan altos niveles de viremia y valores de transaminasas normales o prácticamente normales. La histología hepática muestra ausencia o mínima inflamación y sin fibrosis, pero existe una importante expresión de $\mathrm{HBcAg}$, sobre todo en el núcleo de los hepatocitos. Estos datos sugieren que en esta fase existe cierto grado de inmunotolerancia.

Esta fase puede observarse en aquellos casos en los que la adquisición de la infección se produce en la infancia.

\section{Segunda fase: inmunoeliminación}

Se produce cuando se pierde la inmunotolerancia frente al VHB. Se caracteriza por un aumento de transaminasas y un descenso en los niveles de viremia. En esta fase existe un marcado aumento en los fenómenos inflamatorios y de necrosis, por este motivo disminuye la cantidad de HBcAg. En algunos casos los fenómenos necroinflamatorios son muy severos, conduciendo a la formación de septos fibrosos. Se produce una destrucción de los hepatocitos infectados por el VHB, disminuyendo la replicación viral (expresada por una disminución del DNA viral) y produciéndose la seroconversión de HBeAg a anticuerpos anti-HBe.

La seroconversión en ocasiones es brusca, precedida de un episodio de reactiva- 
ción bioquímica, pero en aproximadamente un tercio de los pacientes, el aclaramiento de HBeAg se produce lentamente, apareciendo en un período de tiempo variable los anticuerpos anti-HBe. La expresión clínica de la reactivación bioquímica es variable, generalmente asintomática, aunque puede dar lugar a cuadros de hepatitis aguda. Poco después de la seroconversión, la bioquímica hepática tiende a normalizarse, el DNA viral es indetectable y únicamente puede detectarse el HBsAg de forma persistente. Es lo que se denomina estado de portador sano de HBsAg.

\section{Tercera fase: portador sano}

En esta fase la analítica hepática es normal, el DNA viral indetectable y el paciente presenta serología de $\mathrm{HBsAg}+$. Esta es la tercera fase de la infección crónica por VHB, es la fase no replicativa de la enfermedad y puede durar largo tiempo, incluso toda la vida del paciente.

La reactivación de la replicación viral puede darse posteriormente en el curso de la enfermedad, bien de forma espontánea o bien como consecuencia de situaciones de inmunosupresión en el huésped, como por ejemplo por tumores sólidos, neoplasias hematológicas o empleo de fármacos quimioterápicos.

La reactivación puede ser silente o dar un cuadro similar al de una hepatitis aguda grave (Fig. 1, 2).

\section{HEPATITIS CRÓNICA HbeAg- (ANTI Hbe+)}

Las hepatitis crónicas causadas por cepas mutantes de VHB que estando en fase replicativa son anti-HBe+ se ven cada vez con mayor frecuencia. Los virus $\mathrm{HBe}-$ son capaces de evadir el sistema inmunitario, provocando infecciones de mayor duración. El curso clínico consiste en repetidas elevaciones de transaminasas seguidas de períodos de remisión. La reactivación viene precedida por un aumento en la replicación viral (que puede medirse por la cantidad de DNA viral) asociado a un aumento en los títulos de anticuerpos antiHBc IgM. La frecuencia, duración y severidad de los episodios es variable. Los períodos de remisión se caracterizan por niveles prácticamente normales o mínimamente

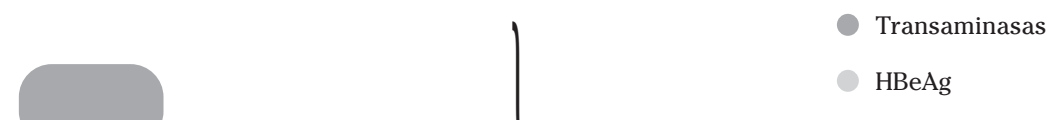

Fase 1

Fase 2

Fase 3

Figura 1. Esquema de niveles de trasaminasas y HBeAg en las distintas fases de la hepatitis crónica por VHB. 
elevados de transaminasas, así como por bajos niveles de DNA VHB. Las reactivaciones repetidas causan un daño hepático que puede conducir a la cirrosis. Los episodios de reactivación disminuyen en frecuencia conforme avanza el tiempo y tienden a ser menos severos, pudiendo llegar incluso a un período de remisión sostenida que incluye un aclaramiento del HBsAg y el desarrollo de anticuerpos anti-HBs.

\section{ACLARAMIENTO DEL HBsAg}

El aclaramiento espontáneo del $\mathrm{HBsAg}$ es relativamente infrecuente. Suele ocurrir hacia el final de la infección y parece ser más frecuente en pacientes con cirrosis. Suele acompañarse de la aparición de anticuerpos anti-HBs y representa el final de la infección crónica por VHB. Generalmente las pruebas hepáticas son normales.

\section{EVOLUCIÓN A CIRROSIS}

El desarrollo de cirrosis se ha asociado estrechamente a un balance desfavorable entre la replicación del VHB y la inmunidad frente al virus, que es incapaz de controlar la replicación, pero causa daño hepático. La aparición de cirrosis es más frecuente en los pacientes que no presentan seroconversión hacia anti-HBe y mantienen la replicación del virus a pesar de repetidos episodios de exacerbaciones bioquímicas, en aquellos que presentaron descompensación hepática durante las exacerbaciones o en aquellos que presentaron reactivaciones, sobre todo con reaparición del HBeAg.

La presencia de hepatitis crónica activa en la biopsia inicial no se ha asociado al desarrollo de cirrosis. La presencia de puentes de fibrosis o necrosis y replicación viral persistente o picos de exacerbación se han asociado con mayor frecuencia al desarrollo de cirrosis en aquellos pacientes anti-HBe+.

El desarrollo de cirrosis en pacientes con enfermedad subclínica, tiene relativo buen pronóstico.

En algunos estudios se han analizado distintos factores asociados a muerte durante el seguimiento de la hepatitis crónica por VHB. Entre ellos se encuentran la edad avanzada, niveles bajos de albúmina, niveles bajos de plaquetas, bilirrubina elevada, presencia de esplenomegalia y positividad para HBeAg en el momento del

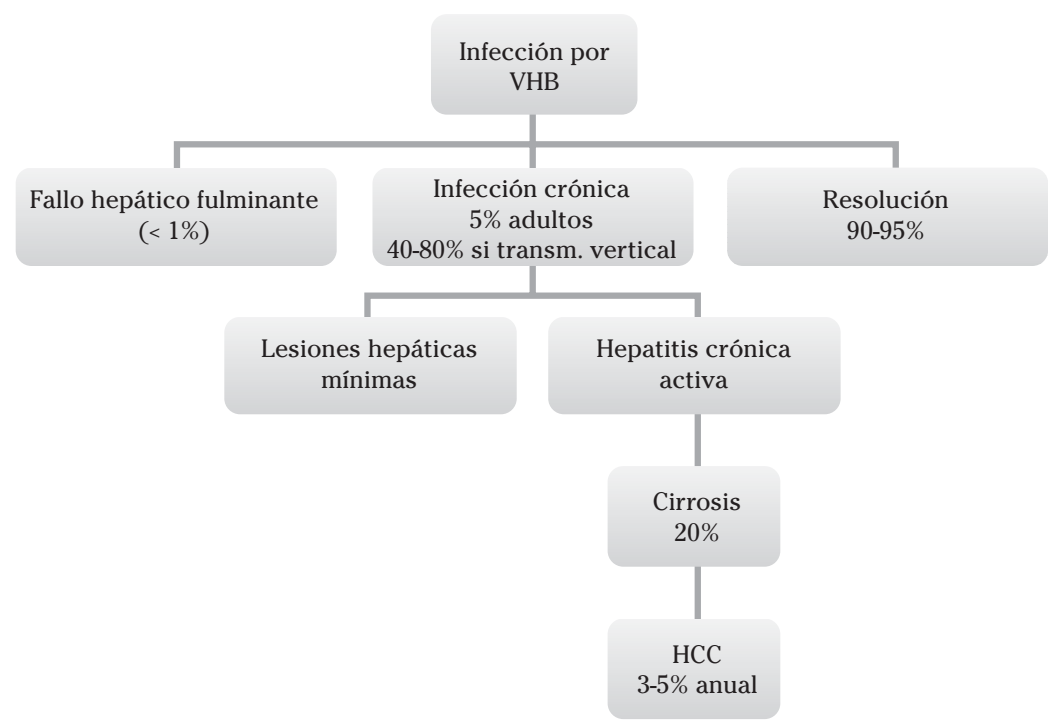

Figura 2. Cuadro resumen de la evolución de la infección por el VHB. 
diagnóstico. En cambio, el cese de la replicación viral y/o la remisión bioquímica durante el transcurso de la enfermedad se correlacionan de modo significativo con una mejor supervivencia.

\section{VHB Y HEPATOCARCINOMA}

El hepatocarcinoma (HCC) ${ }^{8}$ se desarrolla especialmente en aquellos pacientes con cirrosis. Estudios epidemiológicos indican que la edad, el sexo masculino, agentes químicos como la aflatoxina, el abuso de alcohol, las hormonas, las enfermedades metabólicas, las hepatitis virales y la cirrosis hepática son los factores de riesgo más importantes para el desarrollo de hepatocarcinoma. El VHB y el VHC parecen los factores más importantes ya que se encuentran presentes en el $70-80 \%$ de los casos de HCC. La necrosis hepatocitaria secundaria a la infección crónica por VHB activa una respuesta inflamatoria con producción de varias citoquinas. Algunas de ellas inducen en las células hepáticas la entrada en el ciclo de proliferación celular, pudiendo provocar daños de reparación del DNA. Por otro lado la fibrosis altera la estructura normal del hígado mediante la modificación de las interacciones célula-célula o célula-matriz extracelular lo cual puede llevar a una pérdida en el control del ciclo celular. A pesar de que la mayoría de HCC aparecen en el hígado cirrótico pueden verse casos de HCC sobre hepatitis crónica activa por VHB.

Otros mecanismos por los que el VHB es oncogénico parecen ser la integración del DNA viral en el DNA hepatocitario, la activación de oncogenes o genes supresores de tumor y el reordenamiento cromosómico.

\section{BIBLIOGRAFÍA}

1. Moreno R, García L, García C. Inmune response to hepatitis $\mathrm{B}$ virus. En: Viral hepatitis. Butí M, Esteban R, Guardia J, Eds. $2000,9$.

2. LAVANCHY D. Hepatitis B virus epidemiology, disease burden, treatment, and current and emerging prevention and control measures. J Viral Hepat 2004, 11: 97-107.

3. Lung C, Ratziu V, Yuen M, Poynard T. Viral hepatitis B. Lancet 2003; 362: 2089-2094.

4. SÁNCHEZ-TAPIAS JM. Natural history of chronic hepatitis B. En: Viral hepatitis. Butí M, Esteban R, Guardia J, Eds. 2000, 21.

5. Lock A, McMahon B. Chronic hepatitis B. Hepatology 2001; 6: 1225-1241.

6. Hadziyannis S, Vassilopoulos D. Hepatitis B e Antigen-Negative Chronic Hepatitis B. Hepatology 2001, 4: 617-624.

7. GANEM D, Prince A. Hepatitis B Virus infectionNatural history and clinical consequences. N Eng J Med 2004; 350; 11: 1118-1129.

8. CASTELLS LL. Hepatitis B virus and hepatocellular carcinoma. En: Viral hepatitis. Butí M, Esteban R, Guardia J, Eds. 2000, 33. 